Acta Poetica $35 \cdot 2$

JULIO-DICIEMBRE

$2014(119-136)$

\title{
"Nacimiento de la pasión que se busca en el núcleo de su vida". Aproximaciones al sufismo desde un poemario de Francisco Magaña
}

\author{
Diana Rodríguez Vértiz
}

En el año de 1992 Francisco Magaña publica su tercer poemario, Calendas, la mirada, en la colección "El ala del tigre" de la Universidad Nacional Autónoma de México. La añoranza por un tiempo pasado se propone desde el título y es reforzada por el epígrafe de apertura, perteneciente al poeta místico persa Jalal al-Din Rumi: "Estuvimos en el cielo, éramos amigos / de los ángeles; Padre, déjanos / regresar allí, pues ésa es nuestra / tierra". Son abundantes los intertextos e hipertextos que presenta este poemario con temas propios del sufismo. El llamado a la contemplación, la relación con la música y la danza, las imágenes del samá, la infancia y el amor como vía de unión con lo divino, son algunos de los tópicos más recurrentes en este poemario, en el cual, el poeta tabasqueño, más que participar en una experiencia mística propia del sufismo, escribe maravillado el descubrimiento de esta tradición.

palabras clave: Islam en México, poesía, sufismo, Francisco Magaña.

In 1992, Francisco Magaña published his third book of poems Calendas, la Mirada, under the collection "El ala de tigre" of the Universidad Nacional Autónoma de México. Nostalgia for a past time is suggested from the title and is reinforced by the opening epigraph, which belongs to the Persian mystical poet Jalal al-Din Rumi: "Estuvimos en el cielo, éramos amigos / de los ángeles; Padre, déjanos / regresar allí, pues ésa es nuestra / tierra". In this book, there are many intertexts and hypertexts referring to typical themes of Sufism. The call to contemplation, the relation between music and dance, the images of samá, childhood and love as a path of union with the divine are some of the more recurrent topics in this book, in which the Tabascan poet, 
rather than participating in a sufi mystical experience, amazed, writes about his discovery of this tradition.

Keywords: Islam in Mexico, Poetry, Sufism, Francisco Magaña.

Fecha de recepción: 10 de noviembre de 2013

Fecha de aceptación: 8 de mayo de 2014 


\author{
Diana Rodríguez Vértiz \\ Universidad Nacional Autónoma de México \\ Facultad de Filosofia y Letras
}

\title{
"Nacimiento de la pasión que se busca en el núcleo de su vida". Aproximaciones al sufismo desde un poemario de Francisco Magaña
}

Hablar del Islam en México nos pone en una situación desventajosa en cuanto al registro de su actividad (por lo menos institucional) respecto a otras religiones. La imposición violenta del catolicismo durante la Colonia, así como la tardía promulgación de la libertad de culto en el país, hasta la segunda mitad del siglo XIX, ocultaron a las minorías religiosas que provenían de diversas latitudes a alimentar nuestro horizonte étnico religioso. En este contexto, resulta de gran interés rastrear el significativo crecimiento que ha tenido la población musulmana en México desde la década del 80 del siglo pasado, sobre todo si tomamos en cuenta que la mayoría de quienes la conforman es conversa (Pastor, "Ser un musulmán en México", 56-57). En 1984 se creó el primer espacio de reunión para la oración musulmana en la ciudad de México, vía el Club Egipcio, y tres años después se fundaría la mezquita de la orden sufi Nur Ashki Jerrahi. El fenómeno de la conversión tomaría una gran visibilidad el año de 1995, tras la consolidación de una orden sufí, parte del movimiento mundial Morabitum, a las afueras de San Cristóbal de Las Casas, Chiapas. En medio de esta expansión del Islam en México, 
en la cual el sufismo desarrolla un papel decisivo, ${ }^{1}$ aparece Calendas, la mirada (1992), cuarto poemario de Francisco Magaña, poeta tabasqueño nacido en Paraíso el año de 1961.

$\mathrm{Si}$ el estudio de las prácticas religiosas oficiales del Islam en nuestro país parecía, hasta hace unas décadas, de difícil acceso, podríamos pensar que la cuestión mística de esta tradición resultaría casi vedada. El caso del sufismo demuestra lo contrario, y tal vez una de las razones por las cuales su expansión se ha desarrollado de una forma más abierta que en otras religiones es su estrecho vínculo con la estética, Michel Random nos recuerda que

los sufíes contemplan la belleza divina, ya sea a través de las cosas sensibles, ya sea directamente en el espejo del corazón [...] se podría, asimismo decir que el sufismo posee, al menos en principio, una "ciencia de lo bello". No es, pues, sorprendente que tenga influencia sobre artes como la poesía, la música e incluso la arquitectura (Rumi: El conocimiento y el secreto, 30).

\section{El llamado}

Calendas, la mirada es un poemario fuertemente receptivo a la tradición antes mencionada. Presenta temáticas esenciales del fenómeno místico, las cuales se hallaban en trabajos previos del autor, tales como la nostalgia, el misterio, el silencio y sus alegorías, alusiones al encuentro con la divinidad, expresiones del proceso ascético, y una frecuente búsqueda de una realidad otra. Si bien estas experiencias se manifestaban en la escritura del tabasqueño sin hacer una referencia directa a una vía religiosa o espiritual determinada, en el libro que nos ocupa encontramos un evidente vínculo con el sufismo. Son diversos los temas e inquietudes, así como las vías de conocimiento y reflexión de la mística islámica planteadas en el poemario de Francisco Magaña. Algunas imágenes y elementos presentes en los versos del tabasqueño que remiten

1 Para más información sobre el papel del sufismo en la conversión al Islam en Europa y América, ver: Nieuwkerk, Women Embracing Islam: Gender and conversion in the West. 
directamente a la vasta y hermosa tradición literaria sufí son los símbolos del fuego y el océano, lo inabarcable, el Amor como fuente primera y motor de todo, y la metáfora del espejo en nuestros corazones.

El primer paratexto, un epígrafe del místico persa Jalal al-Din Rumi, nos introduce a esta tradición y a una de las principales inquietudes que guiará el poemario: el recuerdo y el anhelo de volver al origen.

$$
\begin{aligned}
& \text { Estuvimos en el cielo, éramos amigos } \\
& \text { de los ángeles; Padre, déjanos } \\
& \text { regresar allí, pues es nuestra tierra } \\
& \text { (Rumi ápud Magaña, } \\
& \text { Calendas, la mirada, 9). }
\end{aligned}
$$

Estos fragmentos hacen referencia a la idea de preexistencia desarrollada durante los primeros periodos del sufismo, en el cual algunos místicos como Ali ibn Uthman al-Hujwiri exponían que Dios y el hombre fueron separados después de una armoniosa convivencia. Pues cuando Dios creó los corazones, los espíritus y las facultades más secretas en un ser sumamente bello (los humanos), éstos se llenaron pronto de vanidad; en respuesta a esta actitud, fueron sometidos por El Creador a una vida terrenal donde tendrían que realizar las pruebas necesarias para encontrar los atributos divinos en su estado original. La oración y el designio de los profetas fueron algunos de los caminos indicados. Así, sentimos el primer llamado a emprender la búsqueda de este origen desde la nostalgia por el tiempo extraterrenal de convivencia con lo divino.

Entre las cambiantes y cada vez más enriquecidas definiciones que se han dado del sufismo, así como las inciertas especulaciones sobre el origen de la palabra que denomina este camino espiritual, ${ }^{2}$ hemos decidido definirla, en términos generales, y conforme a la lectura que hace Francisco Magaña en este poemario, como "la dimensión interior del Islam" (Chittick, La doctrina sufi de Rumi, 10), "a path of mystical life, which begins with the soul's conversión, or turning, towards God.

2 Para un desarrollo histórico del término sufí, ver Schimmel, Las dimensiones místicas del Islam y la "Introducción" de Shah a Los sufís. 
The end of this path is human perfection in union with God" (Ernst, Words of ecstasy in Sufism, 1). El camino mediante el cual se plantea esta unión con Dios, es el del Amor.

A pesar de las modificaciones que se han presentado a lo largo del tiempo en las diversas latitudes que han asimilado el sufismo a su propio contexto cultural, podemos encontrar algunos conceptos básicos en esta vía de conocimiento y acercamiento a Dios; nos gustaría destacar las magam y las hal. Las primeras son entendidas como estaciones, pasos que los humanos pueden dar con ayuda divina en el camino místico. Y las hal podrían definirse como aquellas situaciones a las que sólo se puede acceder por el favor de Allah. Para iniciar este recorrido el sufí debe tener una conciencia de la divinidad "de la propia condición humana como capacidad, huella o imagen de Dios y la llamada previa de Dios, sin la que sería imposible que el hombre se pusiera a buscarle: 'mientras no buscas una cosa no la encuentras, excepto el Bien-Amado: a él no le buscas antes de haberle encontrado" (Velasco, El fenómeno místico, 245).

Francisco Magaña es sensible a esta conciencia de la realidad divina, a este llamado, y una vez emprendido el camino de búsqueda hacia la unión con Dios, hace referencia a otra de las más bellas metáforas del sufismo, el velo, como aquel ocultamiento del cual debemos despojarnos para acceder al encuentro con la divinidad, con la Luz. ${ }^{3}$

\author{
LA LLAMA ardiendo tu llama ardiendo mis límites \\ Bebimos del mármol apoteósico festinados en el arrobo \\ $\mathrm{y}$ en los bolsillos piedras para no alejar los pies de \\ la tierra \\ porque una voz bramante \\ conminaba a emprender caminos y retrocediendo
}

Flor aromática esquizada en verosímiles fantasías

flor que devolvería el cráneo lúgubre

${ }^{3}$ Sobre la actualidad de la imagen del velo en el sufismo ver Nicholson, Los místicos del Islam, 32. 
y las veladoras encendidas casi en la parte frontal del velo que hay que destruir

(Calendas, la mirada, 39).

Al despojarnos de los velos, al quedar ciegos del mundo material para poder observar la verdadera belleza divina "el Dios 'sin forma' se manifiesta en el corazón transparente, claro y puro del místico. Pero para preservar el secreto debe mantenerse la oscilación perpetua entre el que se revela ocultándose y se oculta revelándose" (Gonzalo, "El "Ciego vidente'", 198). Situación acompañada de un fuerte sentimiento de nostalgia.

Una de las representaciones más bellas y conocidas de la vía mística sufí, e incluso con la cual se llega a estereotipar esta doctrina, es el Samá, o danza de los derviches giróvagos. Samá quiere decir escuchar y es una danza que se conocía en el mundo islámico desde el siglo IX. Aunque algunos ortodoxos de la época calificaban este baile como una herejía, su implementación como medio de concentración y unidad con lo divino fue un fenómeno extendido, el cual, a pesar de las fuertes censuras promulgadas dentro y fuera de la institución religiosa, ha sobrevivido hasta nuestros días. El Samá tuvo un fuerte impulso por Jalal al-Din Rumi, quien, tras la muerte de su maestro espiritual Shams de Tabriz, implementó con nostalgia la danza que actualmente conocemos y con la cual vemos girar a los derviches de la orden Mevlevi. Parece ser que el mismo Shams fue quien instó a Rumi a realizar los bailes rituales (ver Random, Rumi: El conocimiento y el secreto, Tercera parte "El samá o baile de lo absoluto", especialmente el apartado "Shams a Rumi: dedícate a los bailes rituales", 211-218). El baile del giro tiene un sinfín de significados y alegorías, aquí nos interesa destacar dos en relación con su aparición en el poemario de Magaña. El primero se encuentra relacionado con el movimiento como orden universal, desde los electrones girando alrededor del núcleo del átomo hasta los planetas rodeando al Sol. El giro y el desplazamiento con esta conciencia son representados en la danza. En el poema que abre el libro que nos ocupa, podemos leer: 
Larga, silenciosamenete

con tus caminos desandados y la mirada casi guiño

das el sentido a un mundo maltrecho

Decides que todo gire de nuevo

sobre el vértice fundamental - línea única invisible

Permanecemos interrogados y sin respuestas

con el cuerpo de una incertidumbre densa

pegajosa como una prolongación de hastío

A un lado del cementerio

en sonidos claros distinguibles

las voces del cielo

y el mar un tanto compañero del milagro

(Magaña, Calendas, la mirada, 11).

El segundo elemento que queremos rescatar es el de la música, la cual desarrolla un importante papel en Calendas, la mirada y en toda la producción poética del tabasqueño. Aquí encontramos otro fuerte vínculo con la tradición sufí, y con la práctica del Samá; el mismo Mawlana aceptaba que entre todos los caminos para aproximarse a Dios, él había elegido el de la música y la danza. El baile del giro es un camino de la aniquilación del ego para alcanzar la perfecta unión con la divinidad. El atuendo blanco de los danzantes simboliza el sudario, representación de la renuncia del yo, y la túnica negra con la cual se encuentran cubiertos los bailarines antes de comenzar a ejecutar la danza se relaciona con el nacimiento a la Verdad, se supera la muerte material, del ego, para renacer a la divinidad; el largo bonete color ocre que acompaña la indumentaria es un símbolo de la lápida. ${ }^{4}$ Encontramos una bella imagen de la música y la muerte en relación con la simbología del Samá en los siguientes versos de Magaña:

4 Podemos encontrar una excelente presentación del Samá y su simbología en el capítulo "La 'Samá' o baile ritual de los derviches giróvagos" de Luce López-Baralt y Lorenzo Piera en El sol a media noche. La experiencia mistica: tradición y actualidad, 215-226. 
MÚSICA ATMÓSFERA tibia liviana y monocorde

Esos pasos esos primeros pasos

y esa costumbre de morir la vida dentro y

fuera de nuestros cuerpos dueños del Ser

Cíngulo

gracia divina que nos mantiene ceñidos

a esperanzas

La mirada serena del enterrador

Blanca la imagen de él

(Calendas, la mirada, 42).

\section{El ya amado}

Calendas coloquialmente se entiende como una "época o tiempo pasado", o aquella situación que jamás acontecerá. "A calendas griegas" es una expresión, poco utilizada en nuestros días, que designa una imposibilidad. En Roma la calenda se refería, siguiendo el cómputo eclesiástico, al primer domingo de cada mes, y a la "lección del martirologio romano, con los nombres y hechos de los santos, y las fiestas pertenecientes a cada día" (DRAE). El título del poemario del tabasqueño se relaciona con varios elementos de todas estas significaciones. Desde una primera lectura de los versos que lo componen podemos detectar la fuerte alusión a espacios del pasado, a los cuales es prácticamente inaccesible volver, el tema de la infancia es uno de los tópicos más evidentes:

VOLVER al barrio de juegos

a las casas de teja moho y murciélagos

Un caminar distinto sería

ahora que se han marchado las palomas

y que los caballos de alquiler

ahora que muere mi gente

de somnolencia de infarto 
(Su cabello es tanto nieve tantos días

alguien se ha marchado

mientras veo sucumbir las casas de mi vida

que aparecen en otros tonos y con otras voces)

Al referirse a la niñez en la poesía de Jalal al-Din Rumi, Fatemeth Keshavraz afirma que "vía la tonada de nuestra infancia, el sentimiento interno de los poemas da expresión a nuestro llanto al separarnos del origen. Nos hace protagonistas en un breve cuento alegórico: la historia del niño separado de su madre" (Reading mystical lyric, 136). Podemos ubicar esta reflexión en los siguientes versos del poeta tabasqueño:

TIEMPO de nacer llorando en las piernas del amor

El día lo sabe destruye postigos trancas

¿Y si muere la estación?

Quizá mirarnos de frente mirar las hojas destruyendo al tiempo los golpes enguantados en nubes y crepúsculos el rictus agónico desesperante desesperado el rictus nuestro de cada día en las rodillas el temblor la ausencia

La conciencia de este vacío, la calenda entendida como tiempo pasado al cual se añora volver en la cotidianeidad, es un rasgo presente en gran parte de la poesía sufí, y en específico en la de Rumi. "Este extrañamiento, su exilio, sus viajes y los antecedentes sufí de su formación dan a sus obras y su camino un tinte de añoranza, de búsqueda permanente de los orígenes. Todos somos almas arrancadas de la fuente; cuanto decimos proviene del deseo de nombrar al amado" (Ramírez Castañeda, La sed de los peces, 10). Permanente anhelo de retorno, memoria. 
Dhikr significa "recordar". Al ser expulsado de su núcleo, su origen, el hombre se encuentra sumergido en su ego, disperso en sí. Ante la amenaza del olvido de su condición pretemporal, existe una vía de concentración propuesta por el sufismo: el dhikr o "recuerdo de Dios".

La palabra dhikr también significa "invocar", asimismo en su significado técnico sufí "recordar a Dios" también significa "invocar a Dios", y el método central del Camino es la invocación del Nombre divino, el Nombre que es misteriosamente idéntico con el Nombrado, pues es su símbolo perfecto.

[...] es un medio para realizar todos los estados del ser contenidos en la esencia del hombre, o de actualizar todos los nombres que "Dios enseñó a Adán". A través de la invocación el hombre se reintegra en su centro y finalmente alcanza la unión con Dios (Chittick, La doctrina sufí de Rumi, 91-92).

Francisco Magaña escribe sobre la invocación:

FRENTE A nosotros el ribazo donde luego exhumamos cuerpos nombres que adoramos que todos desfilaron enamorados y danzantes

En esta gloria el aliento el cuello blanquecino la sedosidad que recorrieron mis dedos perpetuados en el columbario cuando una voz preguntaba quién sabrá de estas hazañas apresadas en el clímax (Calendas, la mirada, 36).

Entre las primeras congregaciones sufíes de Bagdad el camino hacia la Unidad era explícito en el reconocimiento de Dios en todos los elementos de la vida cotidiana. De esta manera el corazón era concebido como el órgano espiritual de la presencia de la divinidad en los humanos, y sus principales funciones consistían en la "recolección e invocación de Dios" (Karamustafa, Sufism. The formativ period, 19), la práctica del dhikr respondía a esta necesidad de alimento del espíritu vía el recuerdo de la Unidad. Este recuerdo se relaciona también con el pro- 
ceso de renuncia a la existencia terrenal, pues debemos recordar a Dios "constantemente hasta que desaparezca o se aniquile lo humano en el objeto recordado" (Ruiz Figueroa, "Sufismo o misticismo islámico", 122). Es, así, una de las vías por las cuales se busca volver al origen, el cual se encuentra en la Unidad. En los versos de Magaña ubicamos este momento de éxtasis por medio de la invocación, interrumpido por la conciencia de lo efímero que resulta el clímax logrado vía el recuerdo, para volver a desear la unión con lo que representan aquellos "nombres que adoramos".

\section{La llama}

El símbolo del fuego tiene un sinnúmero de connotaciones en el sufismo. En el fana, o la renuncia del ego, este elemento se presenta como purificador del alma, y en esta misma dirección es retomado en el proceso alquímico. "Para Rumi el fuego es el símbolo de aniquilación en las llamas del Amor divino" (Gonzalo, "El agua unida a la llama", párr. 4), y para Hakim Sanā i de Qazna, poeta y místico persa del siglo XII, el amor se definía como un océano de fuego. Pero la llama se presenta en esta tradición mística también como una guía ante la ceguera de quienes aspiran a percibir aunque sea un poco de esta realidad que se encuentra tan cerca e inaccesible a nosotros al mismo tiempo. "En el sufismo, el buscador se parece al ciego que persigue la luz de la que está rodeado, o al loco que reclama la llama con el fin de percibir el día" (Gonzalo, "El 'Ciego vidente'", 196).

Las alusiones al fuego en el poemario de Francisco Magaña se encuentran presentes a través de la imagen de la llama, retomando y resignificando, al mismo tiempo, los sentidos que le da la tradición mística del Islam. En un poema citado líneas arriba, leíamos al comienzo: "LA LLAMA ardiendo tu llama ardiendo mis límites", y en otro poema el autor mexicano escribe:

LEVANTAMOS el muro tenebroso

Ofrenda al cielo a la tierra

Recogemos auroras para colocarlas en desorden 
pero en el océano

ecos interminables que nos abandonan

música de estrellas fulgurante

Un amanecer escarlata en el fondo de las aguas

Tu piel

súbita aparición de un aire desconocido

y no conocemos más que el dolor de tu fuego

en este desierto de mares

(Calendas, la mirada, 14).

Vinculado con experiencias límite, el fuego en los versos del tabasqueño es un elemento presente tanto en la unión como en la nostalgia del Amado. Recordemos las expresiones de éxtasis dentro del sufismo; las shath (frases o aseveraciones dadas en el momento extático) son el resultado del ahondamiento en la más profunda conciencia del corazón, el deseo por el Eterno Amado. Así:

When ecstasy becomes strong and the light of manifestation becomes elevated in the inmost part of their consciences, by the quality of the annunciation and revelation and strengthening of the spirits illuminated by the inspiration that appears in their intellects, its stirs up the fire of their longing for the eternal Beloved. They reach the vision of the seragliocurtain of Majesty, and they are moving in the world of beauty (Ernst, Words of ecstasy in Sufism, 18).

La nostalgia se hace presente una vez salido de este estado ¿De qué manera vivir después de tal experiencia? ¿Cómo compartir, enseñar, aquello que es inefable? Si el pleno significado de estas palabras no puede ser accesible al intelecto humano ¿de qué forma hacer partícipe al prójimo de tal verdad? El encuentro con la belleza genera un fuerte cambio en quien la vive de manera directa, y así, una de las fuentes del sufismo es encontrar la belleza de la divinidad en todo sitio, desde las cosas cotidianas hasta las experiencias cumbre. La búsqueda incesante como respuesta a la nostalgia. La imagen del fuego, la llama, está presente en relación tanto con la consciencia de la belleza 
revelada como de su búsqueda incesante, en los siguientes versos de Magaña:

[...] Solsticio de verano horas de doctrina

paralelas a la plegaria

El escanciador hábil y su suerte

Y una postura de los hornos la correcta

el calor que transmite

en su contacto

las verdades del fuego

Trémula oscilante llama que se incendia en el incendio

en la púrpura perseguida por los antiguos

en el tinte algo morado del molusco

(Calendas, la mirada, 38).

\section{El Amado}

Annemarie Schimmel distingue el camino místico de otras prácticas de búsqueda espiritual, por su intensa relación con el amor; así, "el misticismo podría definirse como amor al Absoluto, pues la fuerza que separa el verdadero misticismo del simple ascetismo es el amor. El amor divino hace al buscador capaz de soportar, incluso de gozar, todas las penas y aflicciones que Dios derrama sobre él para probarle y purificar su alma" (Las dimensiones místicas del Islam, 20). Encontramos esta idea del amor como origen y motor de todo, a lo largo de la tradición sufí. Hafez-e Shirazí, poeta y místico del siglo xIv, escribió:

En la preeternidad emergió en epifanía

la luz de tu hermosura, se reveló el Amor

y prendió fuego al mundo entero

(ápud Elahi, "La poéticay la estética”, 13).

132 RodRíGUEz / Aproximaciones al sufismo desde un poemario de Francisco Magaña 
El amor, fuertemente ligado al impacto que causa la belleza divina, impregna de sentido el camino del sufismo. Durante toda la vía de búsqueda con la Unidad, podemos ubicar esta inmensa fuerza. En los escritos de Rumi, por ejemplo, "Conocimiento y Amor llegan a ser [...] un solo y mismo misterio" (Random, El conocimiento y el secreto, 43). Para llegar al conocimiento del Amado, para develar el secreto del Amor, la vía sufí se erige entre una serie de difíciles y complejas pruebas, el sendero del sufismo como medio del amor afirma la hipótesis de Schimmel sobre la vía mística, pues "el amor es descrito por los sufíes como el remedio de todos los males y la alquimia de la existencia. El amor transforma la pobreza en riqueza, al pobre en príncipe, a la guerra en paz, a la ignorancia en conocimiento y al infierno en cielo" (Elahi, "La poética y la estética", 15).

La experiencia mística suele presentarse como un camino de sufrimiento. Raimon Panikkar se refiere a ella como una profunda experiencia de plenitud. Para los sufíes no podría ser de otra manera, pues están guiados por la inmensa e indefinible fuerza del Amor. Ante las dificultades aparentes, mundanas de este camino, basta la conciencia del Amado.

NO estamos solos no éste es el tiempo de la centella púrpura que enjuaga con sus dedos calmos Y estalla en el aire acortando su distancia artera

Regazo que promulga alumbramientos y alumbramientos agrupados en Su Nombre

Vuelve a la fuente de placer después de ruinas y desvelos vuelve a la plácida verdad que nos conforta

Un cuerpo en vilo una palabra en cierne despierta el día despierta la noche y abre sus ojos la gloria agazapada en el tormento 
Pero un asomo el rostro de un asomo sus fauces alimenta pero la gloria devora los reflejos se mueve el mundo el tiempo su figura

El sueño crece y la verdad se hermanan

Subterráneos emigrantes de nervios extasiados aquí el comienzo cómplice tú y pasión y fuego

Éste es el tiempo verdadero el nuestro (Magaña, Calendas, la mirada, 54-55).

Sobre la poesía de Rumi, Javier Sicilia señala que "semejante a Juan de la Cruz que, después de sentir la experiencia del Amado, lo busca habitándolo, para Rumi la ausencia del Amado es siempre su presencia reflejada en todas las cosas" (Sicilia, "Rumi y la sed de los peces", 12). Así, esta experiencia del Amado nos lleva al "hermoso frenesí" del amor divino, el amante embriagado comienza la búsqueda de renuncia para dar todo al Uno, fundirse, volver a él y convertirse en él. ¿Dónde comenzar este camino? La pregunta resulta pertinente en un contexto de creciente conversión al Islam ¿Qué buscan los nuevos adeptos de esta tradición, aquellos interesados en su corriente mística? Sociológicamente podemos citar motivos variados, los cuales van desde inclusión social, y/o afán de cosmopolitismo, hasta una evidente crisis de espiritualidad, de fe. Francisco Magaña escribe, en medio de esta serie de fenómenos, versos que intentan abarcar su experiencia, su lectura del sufismo en cuanto conciencia de la plenitud; la vía hacia ésta comienza justamente ahí, en el Amor, en su cotidiana presencia.

Allah, el Uno, aquella realidad que rebasa todo ser, todo entendimiento y sentir humano, se encuentra, nos dice el sagrado Corán, "más cerca de nosotros que nuestra propia vena yugular". A finales del siglo $\mathrm{Xx}$, un poeta tabasqueño externo a la comunidad islámica poetiza sobre el sentido del amor, y en medio de sus versos el diálogo con la figura y la poesía de Jalal al-Din Rumi toma suma importancia, pues Rumi fue, nos comparte el Sëyj Ḥassan Dedé, un "profeta del amor [quien] 
vivió para mostrar a los hombres la senda del amor, no importa a qué religión o raza pertenezcan, o qué lengua hablen" (Dedé, 181). ¿Y qué es la experiencia mística, sino el camino del amor? Aquel fenómeno universal común a todas las religiones el cual puede presentarse a cualquier persona, sea parte de una tradición religiosa o de la vida secular. Calendas, la mirada no puede catalogarse como un poemario místico (no son versos dedicados únicamente a dar cuenta de esta experiencia), pero sí podemos reconocer sus páginas como una reflexión en torno a la universalidad de la experiencia mística como aquella vivencia plena del amor, aquel "Nacimiento de la pasión / que se busca en el núcleo de su vida".

\section{REFERENCIAS}

Chiтtick, William C., La doctrina sufi de Rumi, Barcelona, José J. de Olañeta Editor, 2008 (Shophia Perennis).

Elahi Ghomshei, Hossein M., "La poética y la estética en la tradición literaria sufí persa”, en Revista Sufi, otoño/invierno 2002, 12-19. Web. [05/04/13].

ERnst, Carl W., Words of ecstasy in Sufism, Albany New York, State University of New York Press, 1985.

Gonzalo CARbó, Antoni, “El 'Ciego vidente' y el visionario que es 'Todo ojos' en el sufismo”, en El conocimiento y la experiencia espiritual, Agustín López Tobajas y María Tabuyo (eds.), Barcelona, Mandala, 2007, 189-205.

Gonzalo CARbó, Antoni, "El agua unida a la llama. La extinción en el sufismo de Rumi y en la obra de Bill Viola”, Revista Sufi. Web. [05/ 04/ 13 ].

Karamustafa, Ahmet T., Sufism. The formativ period, Berkeley Los Angeles, University of California Press, 2007.

Keshavaraz, Fatemeh, Reading mystical lyric: The case of Jalāl al-Dīn Rumi, Columbia, University of South Carolina Press, 1998.

LóPEZ-BARALt, Luce y Lorenzo Piera (eds.), El sol a media noche: La experiencia mística: tradición y actualidad, Madrid, Trotta / Centro Internacional de Estudios Místicos, 1996.

López ToBajas, Agustín y María Tabuyo (eds.), El conocimiento y la experiencia espiritual, Barcelona, Mandala, 2007.

Magaña, Francisco, Calendas, la mirada, México, Universidad Nacional Autónoma de México, 1992.

Nicholson, Reynold A., Los místicos del Islam, Barcelona, José J. de Olañeta Editor, 2008 (Padma). 
NieUwKerk, Karin van (ed.), Women Embracing Islam: Gender and conversion in the West, Austin, University of Texas Press, 2006.

PASTOR DE MARÍA y CAMPos, Camila, "Ser un musulmán en México: la economía política de la fe", Istor. Revista de Historia internacional, jun. 2011, 54-75.

Ramírez CASTAÑEDA, Elisa (ed.), La sed de los peces, por Jalaludin Rumi, México, Consejo Nacional para la Cultura y las Artes, 2005.

Random, Michel, Rumi: El conocimiento y el secreto, México, Fondo de Cultura Económica, 2006.

Ruiz FigueroA, Manuel, "Sufismo o misticismo islámico", en El Islam en América Latina, Zidane Zeraoui (comp.), México, Limusa / Instituto Tecnológico y de Estudios Superiores Monterrey, 2010, 115-129.

Schimmel, Annemarie, Las dimensiones místicas del Islam, Madrid, Trotta, 2002.

Sнан, Idries, Los sufis, Barcelona, Kairós, 1994.

SiciliA, Javier, "Rumi y la sed de los peces", en La Jornada Semanal, núm. 584, 14 de mayo de 2006.

Velasco, Juan Martín, El fenómeno místico. Estudio comparado, Madrid, Trotta, 2009. 